\title{
Self-emergent peer support using online social networking during cross-border transition
}

\author{
Feng Ding \\ Guangdong University of Foreign Studies, China \\ Paul Stapleton \\ Hong Kong Institute of Education
}

\begin{abstract}
Transitioning from school to university is a major development for learners, often accompanied by difficulties. When overseas students arrive at university for the first time these challenges are multiplied. It is suggested, however, that these difficulties can be mitigated to a certain extent via the use of online social networks. The present study, using data generated by a group of 350 first-year students from mainland China (called QQ), explores how an online instant messaging service helped the students adapt to life in a Hong Kong university. Findings reveal that (a) first-year mainland students experienced specific problems at distinct stages; (b) the QQ provided informational, instrumental and emotional support for the students; (c) the QQ was self-emergent and had a clear annual cycle. It is argued that self-initiated peer support among students plays a vital role in higher education, especially at crucial periods such as school-to-university and cross-border transitions.
\end{abstract}

\section{Introduction}

Research on both school-to-university and cross-border transition has revealed that students need a considerable amount of social support during these critical periods of development in their lives (Pascarella \& Terenzini, 2005; Tao, Dong, Pratt, Hunsberger, \& Pancer, 2000; Wilcox, Winn \& Fyvie-Gauld, 2005). The transition to a new academic and social environment upon entering university is often characterised by weak academic performance, poor psychological well-being or even attrition (Cox, Schmitt, Bobrowski, \& Graham, 2005; Hoffman, Richmond, Morrow, \& Salomone, 2002; Johnson, 2008). Accordingly, studies have been performed to investigate how to help students integrate into their new environment and obtain a sense of belonging as quickly as possible. Peer support has been found to be essential for a smooth transition to university life for many first-year students (Pascarella \& Terenzini, 1983; Tao et al., 2000; Timmis, 2012).

Of particular interest for the present study are the university transition experiences of mainland Chinese students who arrive in Hong Kong for their first year of study at university. Many of these students reported difficulty in adjusting and socialising into the local circle of Hong Kong students due to cultural differences and the need to speak the local language, Cantonese (Cheung, 2013; Xie, 2009). Considering the increasing number of mainland students pursuing higher education in Hong Kong and abroad, more research appears necessary (Cheung, 2013) to understand their adaptation, especially in the first year.

The present study thus investigates spontaneous peer support generated via the use of mobile devices by a group of mainland Chinese students in one of Hong Kong's government-funded universities. By closely observing their instant messaging or chatting records, we identified the kinds of difficulties first-year university students experienced; the type of help they sought from one another; how they helped each other solve problems; and the kinds of functions their social network fulfilled. The ultimate goal of this study was to obtain a better understanding, from the students' own perspective, of how first-year university students coped with their school-university transition, which was further complicated by a cross-border transition.

\section{Literature review}

\section{School-university transition}

Transitioning from school to university can have a great impact on an individual learner's development (Yang, Webster, \& Prosser, 2011), and thus this challenging time in life has become the subject of much research over the past half a century, especially in Anglophone countries (e.g., Johnson, 1994; Pattengale, 
2000; Tinto, 1975; Willcoxson, Cotter, \& Joy, 2011; Wintre, Bower, Gordner, \& Lange, 2006). Complicating this challenge, in the late 20th century, there was a shift from elite to mass tertiary education in many western countries, such as the United States, Britain, New Zealand, and Australia (Schuetze \& Slowey, 2002), which led to a much more complex composition of students on campus in terms of their family and educational background, previous academic performance, and country of origin. It was recognised that failure to cater for the different needs of students could result in a failure to effectively engage them in university life and study (Reason, Terenzini, \& Domingo, 2006; Tinto, 1993). Since the 1990s, therefore, school-university transition has become a phenomenon considered worthy of research (Johnson, 1994; Pattengale, 2000; Wintre et al., 2006; Willcoxson et al., 2011). Despite this new attention on school-to-university transition, however, research has mainly focused on students in native-tongue ( L1) contexts, while tending to ignore overseas students studying in their second language ( L2) who experience an even greater cultural transition.

\section{Cross-border transition}

In fact, many studies have been performed on students undergoing cross-border transitions (Clark \& Gieve, 2006; Gieve \& Clark, 2005; Holliday, 1999; Jin \& Cortazzi, 2006, 2011, 2013; Morita, 2004). However, these have tended to investigate a mixed population including undergraduates and postgraduates from different levels. This may obscure the fact that many first-year overseas students are actually going through double transitions - to university and to a different culture. As a general trend, international students experience more stress than their domestic or local counterparts during the cross-border transition period because they do not have as much social support as domestic students given the distance they are living from their parents, relatives and former friends (Hechanova-Alampay, Beehr, Christiansen, \& Van Horn, 2002; Lin, 2009).

Research on cross-border transition of mainland Chinese students has mainly focused on students pursuing study in English-speaking Anglophone countries (Cheung, 2013); however, in recent years, more and more mainland Chinese students have chosen to study in other places, such as Hong Kong (Gao, 2008). Nevertheless, very few studies have been conducted on mainland Chinese students' adaptation to Hong Kong higher education (Cheung, 2013).

\section{The research context - Hong Kong}

Hong Kong is preferred by many mainland Chinese students for pursuing their higher education not only due to its geographic proximity and its internationally recognised high quality of education, but also due to its unique geopolitical position where Eastern and Western cultures meet; Hong Kong is also viewed as a bridge between mainland China and the outside world.

Although mainland China and Hong Kong share a "similar cultural heritage," the latter has been westernised to a great extent socially, historically, politically and culturally after a century and a half of British colonisation. The education system in Hong Kong "has been largely shaped by British models and practices” and it has remained so even after its turnover to the mainland China in 1997 (Ding, Kuo, \&Van Dyke, 2008, pp. 532-533). With nearly 90\% of tertiary-level academic staff having earned their qualifications in Western countries (Li \& Bray, 2007; Postiglione, 1998, p. 32) and also with a great percentage of native English-speaking academic and administrative staff, Hong Kong universities differ remarkably from those in mainland China in their teaching and administrative culture. Another important feature of higher education in Hong Kong is that English is the major medium of instruction.

\section{Online social support network}

Social support networks are crucial to learner development, especially during the first year of university (Jackson, 2012). An individual's social support network can be made up of parents, relatives, friends and peers. Social support, especially support from peers, is said to be an important buffer to the stress caused during school-university transition (Tao et al., 2000; Timmis, 2012).

Growing up in the information age, undergraduates in the 21st century are all digital natives (Prensky, 2001), with mobile communication and online social networks widespread among them (Timmis, 2012). Online social networking sites have proven to be a popular communication platform for young people, and 
initiatives have been taken by administrative staff or educators in higher education to incorporate digital communication devices to help enhance first-year students' transition to university (Harley, Winn Pemberton, \& Wilcox, 2007; Jackson, 2012). Online social networks have become indispensable among university students, but research into their impact is still “an emerging area” (Jackson, 2012, p. 29).

This study, therefore, addresses the following research questions by exploring how a group of mainland Chinese students studying in a Hong Kong university made use of an online social networking service to solve problems before and after their arrival:

(1) What issues concern a group of mainland Chinese students most at different stages in their first year in a Hong Kong university?

(2) What role does the online social network, QQ, play in the first year of mainland Chinese students' life before and after their arrival at a Hong Kong university?

\section{Data collection}

\section{Data-collecting site and participants}

Data used in this study were the instant texting messages of a group of mainland Chinese students studying at a university in Hong Kong, using an online social network. Tencent QQ, commonly known as QQ, is one of the most popular instant messaging software apps in mainland China. It provides various services including micro-blogging and group and individual chatting. A group of people can establish a group QQ (hereinafter referred to as GQ) for online chatting or information sharing. The GQ investigated in this study was set up by the Chinese Students and Scholars Association (CSSA) in the university where the study was performed for mainland Chinese students to share information and keep in touch with one another. It comprised roughly 350 students.

Although this study did not determine whether there were students without mobile devices, we made a reasonable assumption that close to $100 \%$ of entering students either had smartphones with telephone plans or mobile devices that connected to the Web via campus-wide Wi-Fi. As students could use the Internet nearly anytime and anywhere, they could ask questions through the GQ whenever there was a need.

Many mainland Chinese students found the GQ while searching for information about the university and joined it before their classes began. As a student in this university, the first author was eligible to join the GQ, but for the purposes of this study, she was mainly an observer. From the instant messages, she could observe the interaction among all students.

\section{Data-collection procedures}

Data collection involved two procedures. First, about 4,000 pages of instant messages of the GQ were identified and saved, from September 2, 2012, to October 10, 2013. Most of the students taking an active part were first-year students, although some were senior students from other cohorts. As required by the founder of the GQ, all students enter their year of entry, their names and majors as part of their GQ usernames, making it easy to identify them.

Second, nine first-year mainland Chinese students who were also users of this GQ were interviewed once each to triangulate the findings and help further understand the functions of the GQ and its impact on students. The average duration of each of the nine interviews, conducted in Mandarin Chinese, was 30 minutes.

\section{Data analysis}

The data - 4,000 pages of instant messages - was downloaded and converted into a Word file and then imported into NVivo, a qualitative data analysing software, for coding and categorising, guided by grounded theory (Strauss \& Corbin, 1998). The first round consisted of free coding, with a long list of free nodes generated from the raw data (a node is a topic or a concept) (Bazeley \& Richards, 2000, p. 24). In the second round, these free nodes were built into tree nodes, which are equivalent to categories. Some of the exemplary tree nodes with the free nodes in the brackets included information sharing (looking for 
people, asking about transportation); academic learning (selecting courses, reading); activity organising (ordering food together, buying textbooks); comfort or help seeking (sharing complaints); and difficulties and major concerns (not understanding Cantonese or English well enough).

There were a number of references for each code indicating the frequency of the occurrence of a topic or concepts (see Table 1); for example, the reference for item 7 "what things to bring" was 7 , which meant that this topic was raised 7 times. The most frequently mentioned topics were usually the ones that most concerned students. However, a large amount of messaging was simply teasing, which was a popular way of interacting among the students, and also a process of friendship forging.

Interview data were analysed separately through NVivo in the same manner, mainly focusing on confirming the findings of the chatting record and adding some individual voices.

\section{Findings}

\section{Students' concerns before coming to university}

As noted above, free nodes emerged out of raw data from instant messages. Table 1 shows the most frequent of these before students arrived at the university. At this early stage, the vast majority of messages came in the form of inquiries by the students seeking practical information about how to prepare for university life, such as nodes 1, 2, 3, and 7. Students also asked about average expenses each month, what the weather was like in Hong Kong, and so on. Senior students later created a Q and A list addressing these types of questions and uploaded it to a common space that every member of the GQ could view. The nine interviews confirmed that this list was very helpful when they prepared for arrival at university.

Table 1

Students' major concerns before coming to university

\begin{tabular}{lll}
\hline No. & Free node & No. of references \\
\hline 1 & Transferring money from mainland China to Hong Kong & 16 \\
2 & Transportation to the university and in Hong Kong & 16 \\
3 & Type of telephone to use in Hong Kong & 14 \\
4 & Language of instruction in university & 14 \\
5 & Facilities in the university & 13 \\
6 & Applying for accommodation & 11 \\
7 & Things to bring & 7 \\
8 & Inviting fellow students to go to university & 4 \\
9 & Hotels near the university & 4 \\
10 & Occasions using Cantonese & 2 \\
\hline
\end{tabular}

Nodes 4 and 10 indicate students were worried about the languages of instruction in Hong Kong universities. Although nearly all students were aware that English is the major language of instruction, they were still concerned that it may be too difficult for them. Cantonese, as the language for daily communication, also posed a threat to them.

\section{Students' concerns after arriving at university}

Four main topic areas were identified in the GQ messages after arrival at the university, as indicated in Figure 1, with examples of each type given in Figures 2, 3, 4 and 5 (the number of references is given after each node). 


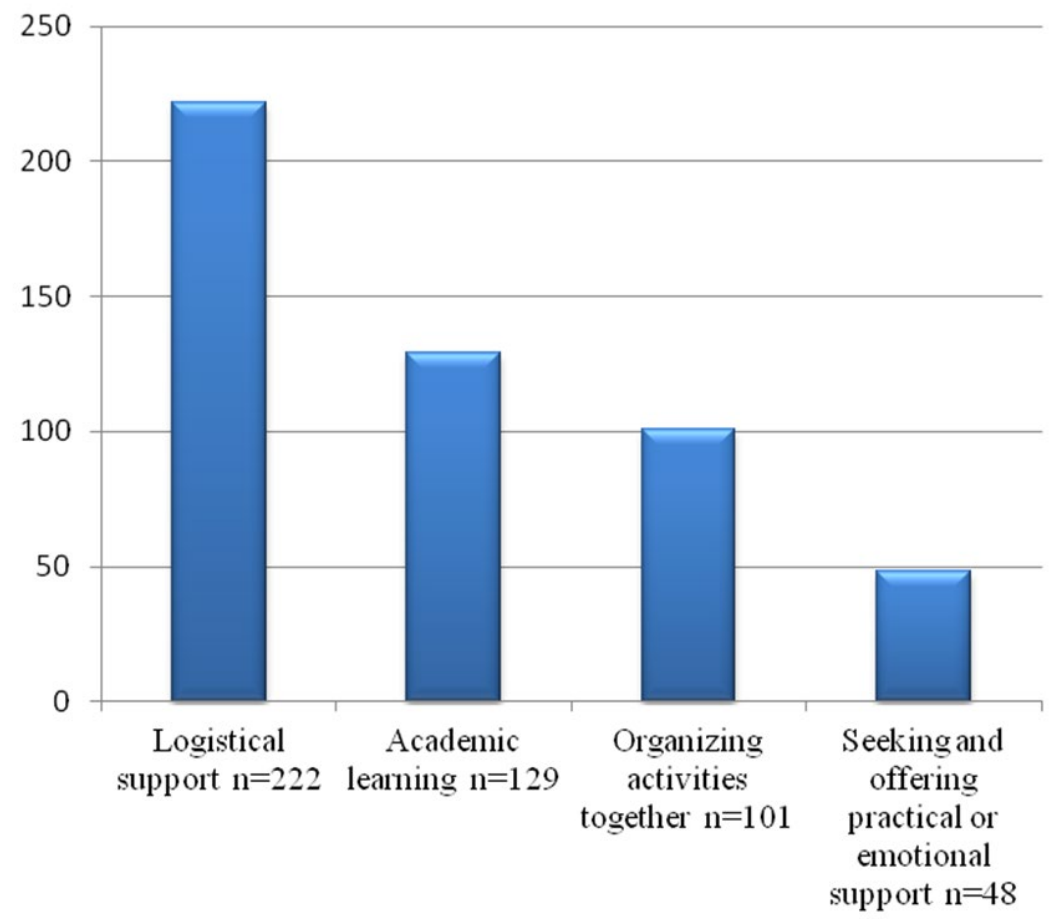

Figure 1. Frequencies of messages by topic areas

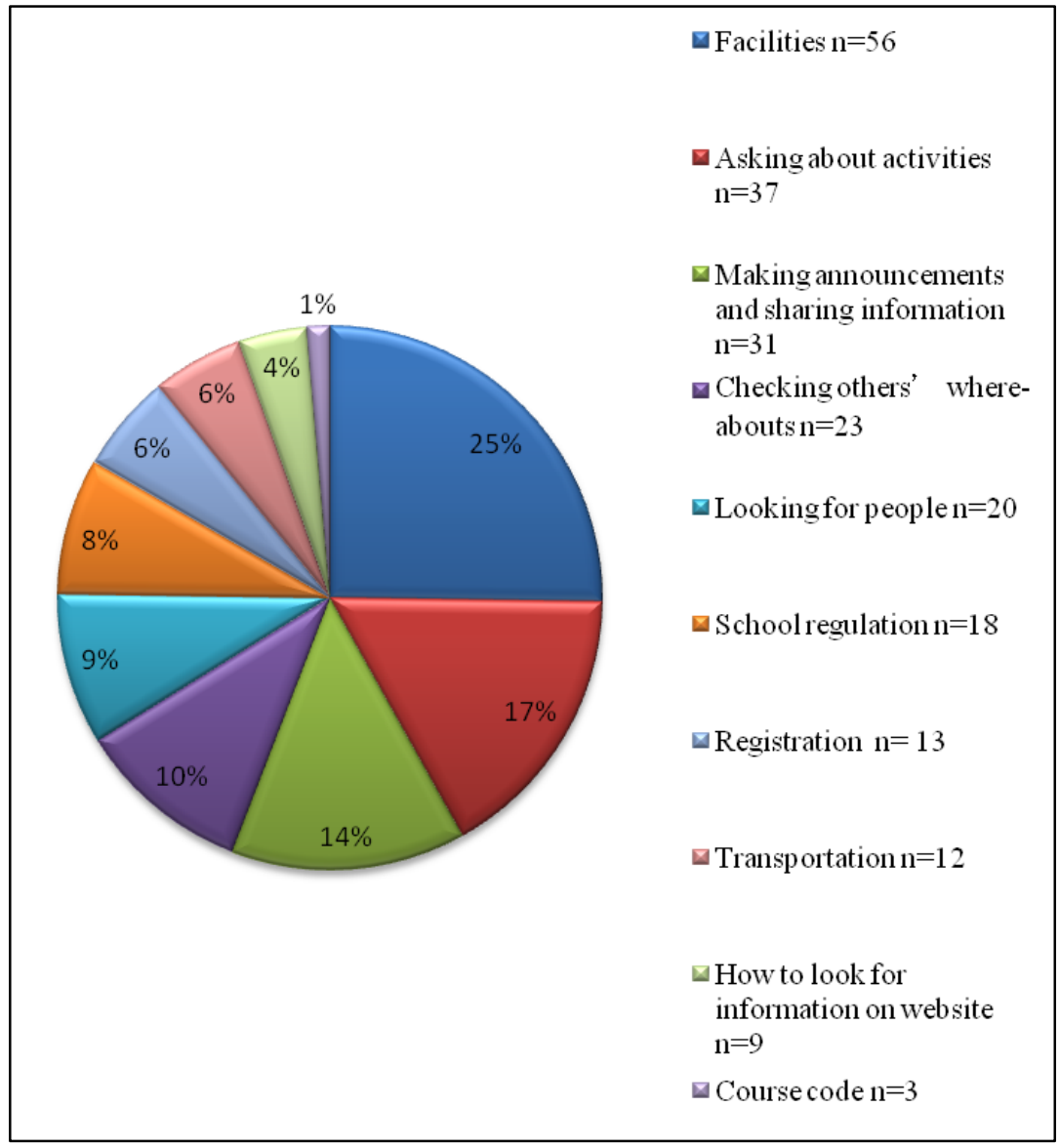

Figure 2. Frequencies of seeking logistical support $(n=222)$ 


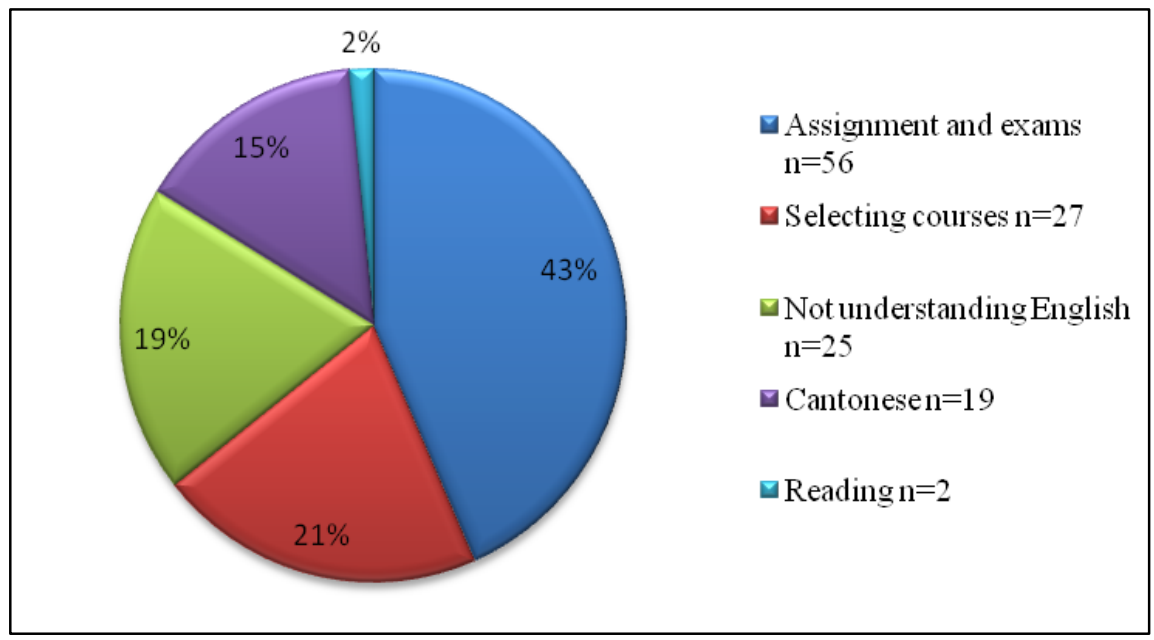

Figure 3. Frequencies of support with academic learning $(n=129)$

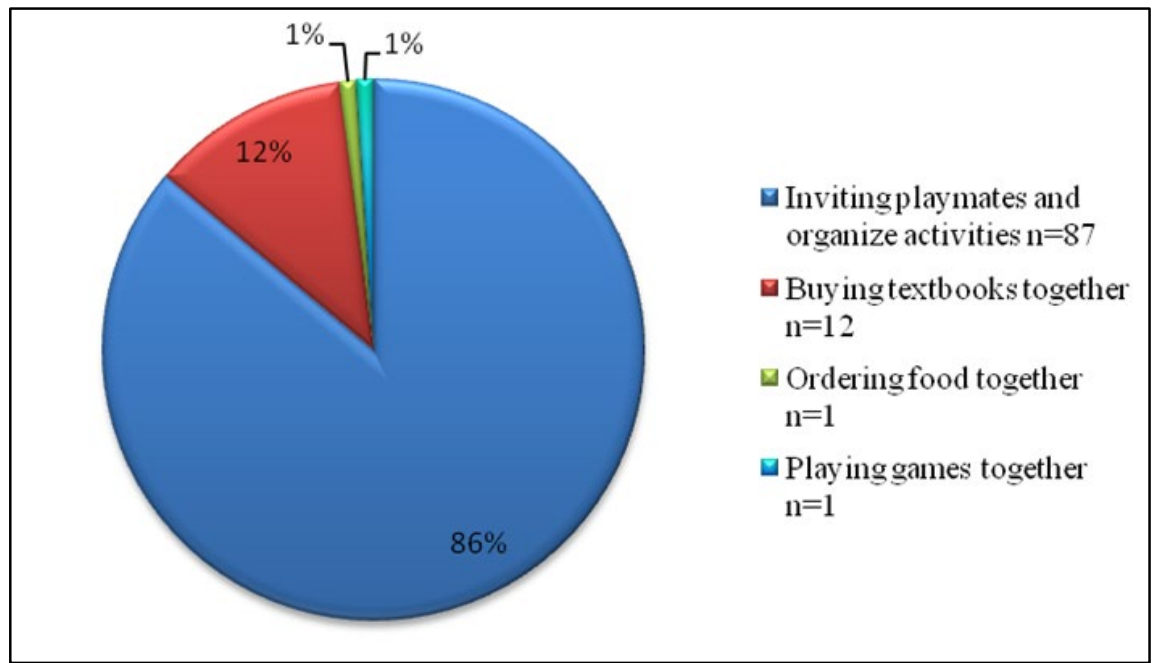

Figure 4. Frequencies for organising activities $(n=101)$

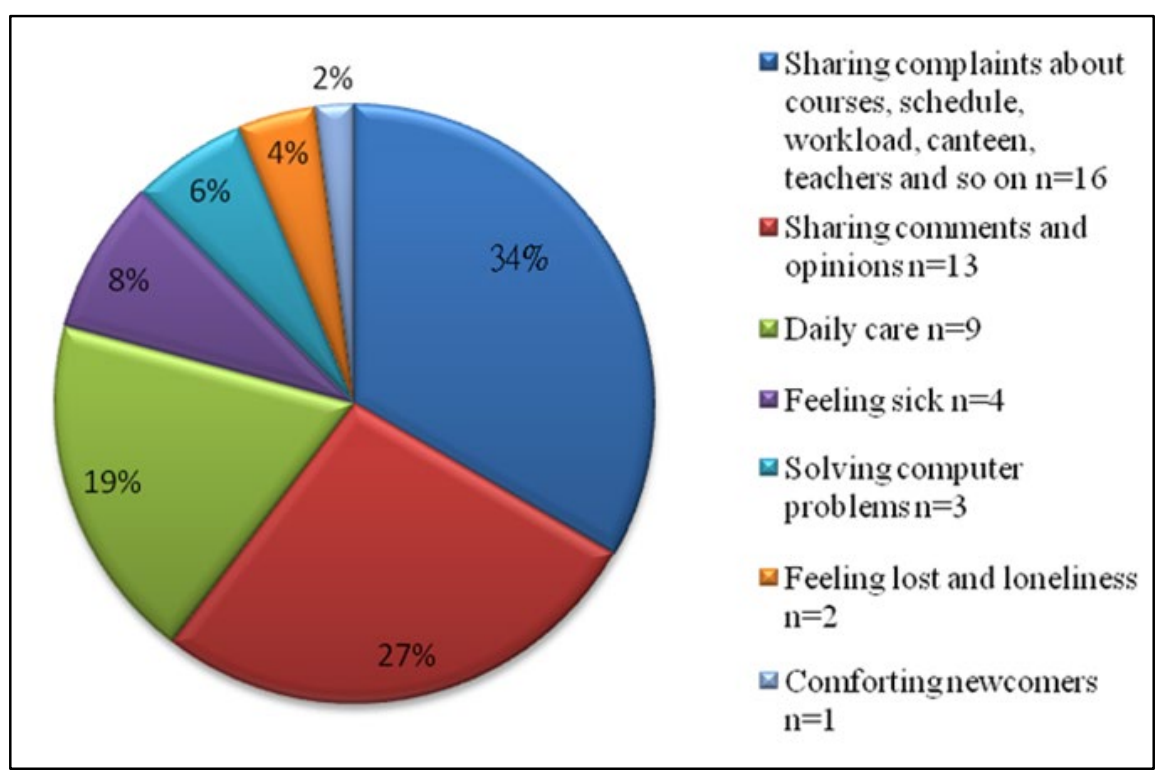

Figure 5. Frequencies of seeking and offering practical and emotional support $(n=48)$ 
The instant messages in the first month after arrival were largely concerned with seeking information related to the logistics of being a student of the university (see Figure 2). As students tried to become familiar with the environment in the first few weeks, they asked questions about a myriad of practical issues. During the first few days, the main topics were about registration and checking into the dormitory. During this time, students frequently exchanged messages about their dormitory room allocations. Other queries included how to switch on the tap in the washroom; how to use the air-conditioners and washing machines; and how to use the sport facilities. As many of them had become familiar with one another through GQ, a certain degree of intimacy quickly developed among the group members even before they had met face-to-face.

Very often, the GQ served as an announcement board where anyone who needed help could leave a message with a very high possibility of getting many responses, as indicated in extract 1 (The original format of a GQ conversation shows the time of the chatting, major of the students and their names and QQ numbers. In order to protect the students' privacy, we have deleted the students' QQ number, major, and their names, and instead indicated different students by using the letters A, B, etc. The original language used in GQ was Chinese. The English is our translation.):

$\begin{array}{ll}\text { Extract } 1 & \\ \text { 5/9/2012 18:26:03 (student A) } & \text { Anybody here? } \\ \text { 5/9/2012 18:26:15 (student B) } & - \text { - } \\ \text { 18:26:23 (student C) } & \text { ? } \\ \text { 18:26:25 (student D) } & \text { I'm here. } \\ \text { 18:26:29 (student D) } & \text { What's up? } \\ \text { 18:26:40 (student E) } & \text { I'm having dinner. } \\ \text { 18:26:46 (student F) } & \text { In the dormitory } \\ \text { 18:26:57 (student D) } & \text { Woke up just now, in bedroom. } \\ \text { 18:27:12 (student A) } & \text { Does anybody have an extra plug adapter? } \\ \text { 18:27:15 (student B) } & \text { I'm on my way to the basketball playground. } \\ \text { 18:27:24 (student A) } & \text { I just got back to Hong Kong. } \\ \text { 18:27:34 (student A) } & \text { Now in dorm, anybody live in Hall B? } \\ \text { 18:27:41 (student B) } & \text { I don't have that thing. } \\ \text { 18:27:44 (student F) } & \text { Yes, I have. } \\ \text { 18:27:48 (student F) } & \text { I'm in Hall B. }\end{array}$

This conversation took place about 10 days after the students had arrived at the university. There were dozens of similar examples of this type in the GQ.

Apart from seeking or sharing information, students also organised activities through the GQ (see Figure 4). For example, in the first few weeks, many mainland Chinese students made plans through the GQ to cook together on weekends. Sometimes, when certain students had food to share, they would leave a message in the GQ, calling whoever happened to see the message to arrange a meal together. Students would then turn this virtual meeting space into a real one. First-year mainland Chinese students who were far from home also appeared to use the GQ to cope with their loneliness. Very often, students used the GQ as an announcement board to look for some company as indicated in Extract 2.

Extract 2

Student A: It's the weekend again. What's everyone doing?

Student A: I just finished the rehearsal.

Student B: Play “Three Kingdoms” [a game]?

Student C: Play badminton?

Student D: Yes.

Student B: Have we booked the court?

Student D: Tomorrow morning.

Student D: We can book now.

Student D: For the morning on the 15th.

Mainland Chinese students in the university under study lived in different dormitories, and the GQ turned out to be the most convenient way of communicating as it was free and a large audience could receive 
messages. For example, when students wanted to go shopping, they would ask in the GQ if anyone was available. If a student wanted to join a sporting activity, she could also use the GQ to invite fellow students.

The interviews reveal that because students had become accustomed to the collective life in secondary school in mainland China, they found it difficult to be alone in the new university environment, so they sought company whenever they could. As the GQ had hundreds of members, it gave the students a very high possibility of finding company when they needed it, at least at the beginning of the first semester before the formal teaching had started and students were not busy.

The GQ also often helped students remind each other about coming academic assessments. Extract 3 is a conversation between a senior (B) and junior student (A); it is only one of many examples showing how senior students served as mentors.

\author{
Extract 3 \\ Student A: The first quiz is before Sept. 22. \\ Student B: Right, you must keep this in mind. \\ Student B: Do you have a quiz each week. \\ Student A: Yes. \\ Student B: You'd better write out all the deadlines and tick one when it's done. \\ Student A: Good idea. \\ Student B: Because there will really be many [deadlines]... \\ Student B: It's really easy to forget the quiz and other activities each week.
}

Students could also seek or offer practical and emotional support to each other (see Figure 5). For instance, they helped each other with daily issues, shared and solved problems together, and comforted each other. When someone was feeling sick, she could ask for help and then many students would offer advice or even medicine.

Starting from the third week, questions became more academic-oriented (see Figure 3). Students were required to choose elective courses after registering for the core courses assigned by the university. Selecting courses proved to be a major difficulty for many students because they were not certain how to make this important decision by themselves. When it was time to select a course, many inquiries were raised to senior students about what courses to select, and which teachers to choose. What concerned the students most was whether the teacher was strict or not. They appeared to avoid courses led by teachers who had high standards and awarded relatively low grades. At this period of time, students exchanged copious information and complaints, as indicated in extracts 4 and 5.

\title{
Extract 4
}

Student A: Even if I have read its description, I still don’t know how to select ...

Student B: So, selecting a course depends a lot on our luck.

Student B: Even if you know what is taught in the course, how do we know whether it's a 'killer' to our GPA.

Student A: I feel that only having a look at the title of the course won't tell us what it's all about.

Student C: I feel really uncertain about the teachers we are going to have for next semester.

Student D: I chose Mr. Smith's course with the same uncertainty last semester.

Student B: When others are worried about course-selecting, we students in the Chinese department have no pressure at all ... our courses are all chosen for us ... although a bit unhappy, we feel relaxed too ... just like the system in mainland Chinese university ... [emoji]

Student A: Don’t you students of Chinese department need to select your own courses?

\section{Extract 5}

Student A: Have you listened to the course introduction in the Orientation?

Student B: Yes, I did, but I still don’t understand it.

Student C: I just wanted to ask whether the explanation is not clear or you didn't get it.

Student B: They really didn't make it clear enough, and I have to select the course tomorrow, very nervous. 
Many students complained that the mail they received from the university was only in English, which was too difficult to understand, confusing them about many activities; this sometimes caused them to miss or ignore the events, as indicated below:

\section{Extract 6}

Student A: So, are there any other activities tomorrow except the one in the library?

Student B: It's all in English.

Student A: Then I'm not going.

A great number of discussions were about students' struggles with Cantonese and English in this period (see Figure 3). Extract 7 took place during class between two first-year mainland students. It was the first time for them to have lectures or workshops delivered all in English. Extract 8, which took place in the middle of a workshop, again underscores language difficulties.

\section{Extract 7}

Student A: What is he talking about? I was absent-minded just now.

Student B: Seems to be about a test in computer application, not very clear... my English sucks.

Student A: Seems that we are going to have a test?

Student B: Yes.

Student A: What is he talking about now?

Student B: Seems that we are going to take the test online? Or on printed out papers?

Student A: What on earth is on the screen?

Student B: When he speaks English, his tongue is never in the right place, I can hardly understand his English.

Student A: ......

Student B: Don't worry, nobody can understand, let's wait for the email.

Student A: Local students seem to understand it.

Student B: Let's ask them.

Student A: I think this foreign teacher is not bad.

Student B: Mm, he is handsome too.

\section{Extract 8}

Student A: I felt lost in the class today.

Student B: It is painful that I don't understand English.

Student C: Feel really worried.

Student B: Please give me subtitles in class!!!!!

Students' frustration in English-medium classes was sometimes exacerbated by the local students' speaking Cantonese in class. Cantonese was a totally new language to many students, which therefore became another communication obstacle for them. Both extracts 7 and 9, however, reveal the opportunities that students took to commiserate in real-time during class.

\section{Extract 9}

Student A: Does anybody feel painful in class?

Student A: I'm now in the class, I'm the only mainland student.

Student B: Yes, I feel painful, feeling that my tongue is tied up.

Student A: I couldn't understand the foreign teacher's English well enough, and what makes things worse is that they use Cantonese in group discussions.

Student B: Lucky me, I'm in the English department, all discussion is in English.

Student A: I'm in the English department too, but they like to discuss in Cantonese!

Student B: But our professor asked us to speak English in class.

Student C: You can ask your tutor to ask the students to speak English in class.

Student A: I feel very frustrated.

Student C: It's painful if you cannot understand the discussion.

Student A: Very depressed.

Student D: I heard that you can ask a group of students to speak English. 
Student E: I have a CLE English class, which is also in English, and I'm the only mainland student too ... and my English is not good ... I'm very sad.

Student D: It's ok to be able to make yourself understood.

Student E: I want to ask others to speak Putonghua.

Student F: Agreed!

Some English classes that were not taught by English native speakers were also reported to be very challenging to students. Quite a few students shared their anxiety and stress and complained about their teachers speaking English with Korean, Japanese or Singaporean accents. It appeared to take them several classes to get used to the different accents of English.

Academic writing was also difficult for many students as they had never written English essays longer than 250 words and were now required to write much longer essays using a formal academic style. In the following conversation, students were worried that their English was too poor to write 1,000 words, and they had no idea what they should write about. The texting in extract 10 took place among a group of English education major students who were chatting about their writing project:

Extract 10

Student A: I don't have the slightest idea (what to do).

Student B: It's true.

Student A: Regarding my poor English, it won’t be possible for me to type out more than 1000 words.

Student B: And it's so troublesome to reference.

Student B: And it's about grammar.

Student A: Right, I'm still not clear about the reference format yet.

Student C: We really suck ... my English is even worse.

\section{Discussion}

The transition to university is an important stage of development for many students accompanied by various challenges, especially when they are simultaneously entering a new culture. The findings from this study suggest that this transition can be made smoother via the use of an online social networking tool that allows free instant messages to be exchanged. This type of network has been shown to have clear advantages over established administrative information structures that can deliver neither instant individualised responses, nor a human touch.

\section{Students' major concerns and difficulties}

As illustrated by the GQ messages in this study, the mainland Chinese students had distinct concerns at different stages. Before they entered university, they were concerned mostly about practical issues, such as requiring information for better preparation. The information provided by senior students proved to be effective, and more importantly gave the newcomers a sense of security and warmth. Getting to know some of their peers even before they arrived on campus gave many students a sense of belonging, which helped to reduce anxiety in the new environment (see Jackson, 2012) as confirmed in the interviews with the nine students.

Becoming familiar with the new organisational culture of a university is an essential step for students before they can effectively adjust to the independent learning mode required in higher education (Harley et al., 2007). Many students in this study experienced a feeling of disorientation and uncertainty at the initial stage. Information delivered to students through orientation programs and course introductions proved to be insufficient as all this information was usually delivered in English, in an intensive manner during the first few weeks while students were still in a disoriented state. Instead of viewing the pre-packaged materials provided by administrators that often lacked immediate relevance (Timmis, 2012), students appeared to prefer the crowd-sourced, self-emergent information that addressed their instant needs, and this was also accompanied by a human touch.

The text messaging reveals that English-medium instruction was one of the major obstacles for most mainland students. They had difficulty understanding lectures and lengthy texts in English; writing essays 
in English was also very challenging. This difficulty caused considerable anxiety for many students to the extent that one of the nine interviewees even considered dropping out of the university in the first two months. Although the students' English had reached a standard for acceptance into a Hong Kong university, in reality, their instant messages reveal that coping with instruction in English was one of their greatest challenges. The wide use of the local language, Cantonese, further complicated their linguistic landscape. For mainland Chinese students who study in Hong Kong universities and have no Cantonese background, the new language is a significant obstacle. Not knowing the local language, while dealing with local students who are either unable or unwilling to communicate in Mandarin Chinese, many mainland students are disadvantaged; their potential socialising circle shrinks dramatically to one mostly made up of mainland students. The GQ appeared to provide a release for students to share their experiences and seek affective support with each other. This gravitation towards one's own nationality may be typical for international students pursuing their education in a foreign place. Without strong motivation to integrate into the local culture, challenges created by a new language of instruction, coupled with loneliness may push some foreign students towards a social network (where there is one) composed entirely of their co-nationals.

\section{Major functions of GQ}

The GQ had three major functions in this study. It provided informational, instrumental and emotional support (see Figures 1-5). A large amount of messaging consisted of information seeking among the students. For new students, the GQ allowed them to better understand the new academic and social environment from senior students in an efficient way even before arriving at the university. Students also offered or got practical (instrumental) help from each other through the GQ, for instance, by borrowing and lending things, and organising activities. Perhaps most importantly, students obtained emotional support from one another by sharing their happiness, loneliness and frustration.

The student management system in Hong Kong universities is very different from that of mainland China. In nearly all mainland Chinese schools or universities, students are administered in a ban (or class, if translated into English), which means students in a ban usually study and socialise together throughout their school or university life (Tao et al., 2000). They mostly have the same classes at the same time making it easy for students to achieve a sense of belonging and to find friends in a short time. In the university where we performed the present study, students did not have a fixed ban. Students changed classrooms for different courses; thus, it was very difficult to find two students with exactly the same classes. Without a ready social network, it would have been difficult for students to find stable company in a short period of time; therefore, the GQ went some distance towards fulfilling the role of group making.

In the GQ, mentorship existed especially between senior and junior students. As indicated above, a Q and A list was composed by senior students to offer practical help to the junior students for their preparation towards university life. Senior students also helped newcomers with course selection and shared their own ways of coping in first year. Peer mentorship has been demonstrated as one of the many ways to help firstyear students adapt well to university life (Snowden \& Hardy, 2012). It reduces the mentees' anxiety, while helping them engage in the new community earlier. By helping others, the students in the mentor role also obtained a sense of fulfillment, which should have enhanced their feeling of self-worth. All of these mentoring benefits emerged from the online social network.

\section{Pitfalls and possible solutions}

Some studies have suggested that unregulated use of digital devices, including the use of online social networking devices during class, negatively affect students' academic performance (Ragan, Jennings, Massey, \& Doolittle, 2014; Ravizza, Hambrick, \& Fenn, 2014). As noted above, several conversations (extracts 6, 7 and 9) took place during classes or workshops. In this sense, online social networking may be blurring the boundaries of formal learning settings and students' social life. While it can provide necessary support to the students, it is sometimes a distraction to their learning. For example, in extract 7, after comforting each other, the two students discussed the appearance of the teacher.

As explained earlier, it appeared to be natural for students to turn to their co-nationals under circumstances where access to the host environment posed difficulties. However, once the students felt comfortable in the social network of their co-nationals, they became less motivated to integrate into the new culture. In this sense, the GQ may have deterred interactions with local students, and culture, which in turn may have 
postponed or even thwarted their adaptation to the local environment and to some extent sacrificed their experience as international students. Most mainland students formed their own cliques because they knew little Cantonese, and the comfort they enjoyed by studying and socialising together made it more difficult to learn the local tongue. Thus, online social networks that encourage a better natural integration of firstyear international students into university life and local culture need to be devised. For instance, including trained staff or local students in similar social networks may help promote international students' integration into local culture.

\section{Conclusion}

This study illustrates that social support networks are crucial for first-year university students' successful adjustment to university life and study. Similar to Timmis (2012), who explained the important role of peer support in collaborative learning via online social networking, this study deepens our understanding of the lived experience of students' application of self-emergent peer support on a broader scale, in both life and study during a transitional period. By analysing the instant messages of a group of mainland Chinese students studying in a Hong Kong university over one and a half years, this study explored how they provided informational, instrumental and emotional support to each other using an instant messaging service.

Although this study was performed in one context (Hong Kong) over a short period of time, its findings may be applicable to other contexts that involve international students or first-year students in university. Given the growing number of international students - which, by one account, doubled between 2000 and 2012 and now represents 20\% of the tertiary sector (United Nations Educational, Scientific and Cultural Organization, 2014) - university administrators may take note of both the merits and drawbacks of online networks used by international students and monitor them and take action where deemed necessary. Suffice to say, however, these networks, by their very nature, are emergent and subject to only limited, if any, control at all.

In the end, both school-to-university transition and cross-border transitions entail the interruption of the students' old social network, both on- and offline, and the establishment of a new one. As these transitional periods are often difficult to manage for educational institutions, especially in an era of tight fiscal constraint at the tertiary level, self-emergent peer support through online social networking can play an indispensable role in smoothening the transition and mitigating students' stress. Peer support should, therefore, be viewed as a fundamental supplement to the management of the host university.

\section{Acknowledgements}

We would like to thank Professor Phil Benson and Professor Ann Johns for reading the drafts of this paper. Our gratitude also goes to the two anonymous reviewers and the editors for their constructive suggestions.

\section{Funding}

This research was supported by Fund of the Characteristic Project (Social Science) -- Enhancing the University through Innovation -of the Department of Education of Guangdong Province in 2014. The title of the project is: Investigating mainland Chinese students' transition to a Hong Kong university: from the perspective of learner autonomy.

\section{References}

Bazeley, P., \& Richards, L. (2000). The NVivo qualitative project book. London: Sage.

Cheung, C. (2013). Language, academic, socio-cultural and financial adjustments of Mainland Chinese students studying in Hong Kong. International Journal of Educational Management, 27(3), 221241. doi:10.1108/09513541311306459

Clark, R., \& Gieve, S. N. (2006). On the discursive construction of 'the Chinese learner'. Language, Culture and Curriculum, 19(1), 54-73. doi:10.1080/07908310608668754

Cox, P., Schmitt, P., Bobrowski, \& Graham, G. (2005). Enhancing the first-year experience for business students: Student retention and academic success. Journal of Behavioral and Applied Management, 7(1), 40-68. Retrieved from 
http://www.ibam.com/pubs/jbam/articles/vol7/JBAM\%20September\%202005.pdf

Ding, Y., Kuo, Y. L., \& Van Dyke, D. C (2008). School psychology in China (PRC), Hong Kong and Taiwan: A cross-regional perspective. School Psychology International, 29(5), 529-548. doi:10.1177/0143034308099200

Gao, X. (2008). Shifting motivational discourses among Mainland Chinese students in an English medium tertiary institution in Hong Kong: A longitudinal inquiry. Studies in Higher Education, 33(5), 599-614. doi:10.1080/03075070802373107

Gieve, S., \& Clark, R. (2005). 'The Chinese approach to learning': Cultural trait or situated response? The case of a self-directed learning programme. System, 33(2), 261-276. doi:10.1016/j.system.2004.09.015

Harley, D., Winn, S., Pemberton, S., \& Wilcox, P. (2007). Using texting to support students' transition to university. Innovations in Education \& Teaching International, 44(3), 229-241. doi:10.1080/14703290701486506

Hechanova-Alampay, R., Beehr, T., Christiansen, N., \& Van Horn, R. K. (2002). Adjustment and strain among domestic and international student sojourners: A longitudinal study. School Psychology International, 23(4), 458-474. doi:10.1177/0143034302234007

Hoffman, M., Richmond, J., Morrow, J., \& Salomone, K. (2002). Investigating "sense of belonging” in first-year college students. Journal of College Student Retention, 4(3), 227-256. doi:10.2190/DRYCCXQ9-JQ8V-HT4V

Holliday, A. (1999). Small cultures. Applied Linguistics, 20(2), 237-264. doi:10.1093/applin/20.2.237

Jackson, V. (2012). The use of a social networking site with pre-enrolled business school students to enhance their first year experience at university, and in doing so, improve retention. Widening Participation \& Lifelong Learning, 14, 25-41. doi:10.5456/WPLL.14.S.25

Jin, L., \& Cortazzi, M. (2006). Changing practices in Chinese cultures of learning. Language, Culture and Curriculum, 19(1), 5-20. doi:10.1080/07908310608668751

Jin, L., \& Cortazzi, M. (2011). Researching Chinese learners: Skills, perceptions and intercultural adaptations. Basingstoke: Palgrave Macmillan. doi:10.1057/9780230299481

Jin, L., \& Cortazzi, M. (2013). Researching intercultural learning: Investigations in language and education. Basingstoke: Palgrave Macmillan.

Johnson, G. (1994). Undergraduate student attrition: A comparison of the characteristics of students who withdraw and students who persist. Alberta Journal of Educational Research, 40, 337-353..

Johnson, I. (2008). Enrollment, persistent and graduation of in-state students at a public research university: Does high school matter? Research in Higher Education, 49, 776-793. doi:10.1007/s11162-008-9105-8

Li, M., \& Bray, M. (2007). Cross-border flows of students for higher education: Push-pull factors and motivations of Mainland Chinese students in Hong Kong and Macau. Higher Education, 53(6), 791818. doi:10.1007/s10734-005-5423-3

Lin, C. H. (2009). Exploring facets of a social network to explicate the status of social support and its effects on stress. Social Behavior \& Personality: An International Journal, 37(5), 701-710. doi:10.2224/sbp.2009.37.5.701

Morita, N. (2004). Negotiating participation and identity in second language academic communities. TESOL Quarterly, 38(4), 573-603. doi:10.2307/3588281

Pascarella, E. T., \& Terenzini, P. T. (1983). Predicting voluntary freshman year persistence/withdrawal behavior in a residential university: A path analytic validation of Tinto's model. Journal of Educational Psychology, 75(2), 215-226. doi:10.1037/0022-0663.75.2.215

Pascarella, E. T., \& Terenzini, P. T. (2005). How college affects students: A third decade of research (2nd ed.). San Francisco, CA: Jossey-Bass.

Pattengale, J. (2000). Politics and practices to enhance sophomore success. In L. A. Schreiner \& J. Pattengale (Eds.), Visible solutions for invisible students: Helping sophomore succeed (pp. 31-45). Columbia: University of South Carolina, National Resource Center for the First-Year Experience and Students in Transition.

Postiglione, G.A. (1998). Maintaining global engagement in the face of national integration in Hong Kong. Comparative Education Review, 42(1), 30-45. doi:10.1086/447477

Prensky, M. (2001) Digital natives, digital immigrants: Part 1. On the Horizon, 9(5), 1-6. doi:10.1108/10748120110424816

Ragan, E. D., Jennings, S. R., Massey, J. D., \& Doolittle, P. E. (2014). Unregulated use of laptops over time in large lecture classes. Computers \& Education, 78(0), 78-86.

doi:10.1016/j.compedu.2014.05.002 
Ravizza, S. M., Hambrick, D. Z., \& Fenn, K. M. (2014). Non-academic internet use in the classroom is negatively related to classroom learning regardless of intellectual ability. Computers \& Education, 78, 109-114. doi:10.1016/j.compedu.2014.05.007

Reason, R., Terenzini, P., \& Domingo, R. (2006). First things first: Developing academic competence in the first year of college. Research in Higher Education, 47(2), 149-175. doi:10.1007/s11162-0058884-4

Schuetze, H. G., \& Slowey, M. (2002). Participation and exclusion: A comparative analysis of nontraditional students and lifelong learners in higher education. Higher Education, 44(3), 309-327. doi:10.1023/A:1019898114335

Snowden, M., \& Hardy, T. (2012). Peer mentorship and positive effects on student mentor and mentee retention and academic success. Widening Participation \& Lifelong Learning, 14, 76-92. doi:10.5456/WPLL.14.S.76

Strauss, A. L., \& Corbin, J. M. (1998). Basics of qualitative research: Techniques and procedures for developing grounded theory (2nd ed.). Thousand Oaks, CA: Sage.

Tao, S., Dong, Q., Pratt, M. W., Hunsberger, B., \& Pancer, S. M. (2000). Social support: Relations to coping and adjustment during the transition to university in the People's Republic of China. Journal of Adolescent Research, 15(1), 123-143. doi:10.1177/0743558400151007

Timmis, S. (2012). Constant companions: Instant messaging conversations as sustainable supportive study structures amongst undergraduate peers. Computers \& Education, 59(1), 3-18. doi:10.1016/j.compedu.2011.09.026

Tinto, V. (1975). Dropout from higher education: A theoretical synthesis of recent research. Review of Educational Research, 45, 89-125. doi:10.3102/00346543045001089

Tinto, V. (1993). Leaving college: Rethinking the causes and cures of student attrition (2nd ed.). Chicago, IL: University of Chicago Press.

United Nations Educational, Scientific and Cultural Organization. (2014). Global flow of tertiary-level students. Paris: Author. Retrieved from http://www.uis.unesco.org/Education/Pages/international-student-flow-viz.aspx

Wilcox, P., Winn S., \& Fyvie-Gauld, M. (2005). 'It was nothing to do with the university, it was just the people': The role of social support in the first-year experience of higher education. Studies in Higher Education, 30(6), 707-722. doi:10.1080/03075070500340036

Willcoxson, L., Cotter, J., \& Joy, S. (2011). Beyond the first-year experience: The impact on attrition of student experiences throughout undergraduate degree studies in six diverse universities. Studies in Higher Education, 36(3), 331-352. doi:10.1080/03075070903581533

Wintre, M., Bower, C., Gordner, N., \& Lange, L. (2006). Re-evaluating the university attrition statistic: A longitudinal follow-up study. Journal of Adolescent Research, 21, 111-132. doi:10.1177/0743558405285658

Xie, X. Y. (2009). Mainland Chinese students' adjustment to studying and living in Hong Kong (Unpublished doctoral dissertation). University of Leicester.

Yang, M., Webster, B., \& Prosser, M. (2011). Exploring the variation in first year undergraduates' induction into their academic disciplines. International Journal for the Scholarship of Teaching \& Learning, 5(1), 1-18. Retrieved from http://digitalcommons.georgiasouthern.edu/ij-sotl/vol5/iss1/13/

Corresponding author: Feng Ding, 200010215@oamail.gdufs.edu.cn

Australasian Journal of Educational Technology (c) 2015.

Please cite as: Ding, F., \& Stapleton, P. (2015). Self-emergent peer support using online social networking during cross-border transition. Australasian Journal of Educational Technology, 31(6), 671-684. 